\title{
POLICY LEARNING IN REGIONAL NETWORKS
}

\author{
Arthur Benz \\ FernUniversität Hagen, Germany \\ Dietrich Fürst \\ Universität Hannover, Germany
}

\begin{abstract}
The article contributes to the current discourse on learning regions. It aims to identify favourable conditions for policy learning in regions. Supported by the most prominent theories on regional development and innovation, the existence of autonomous policy networks in regions is regarded as a fundamental prerequisite for generating innovations. However, previous research does not clarify how networks have to be organized and linked to the institutional framework inside and outside a region, how actors should interact in networks, and whether competitive or cooperative orientations of actors are more conducive to change. Our theoretical reasoning leads us to the conclusion that learning regions are those that
\end{abstract}

manage to meet different, to a certain degree contradictory, demands regarding structures of networks and actors involved. Successful learning, the generation and implementation of new patterns of politics and new policies depends on specific structural characteristics of networks, but also on actors' cognitive dispositions, orientations, strategies and interactions. Moreover, favourable institutional settings are identified which may induce adequate network structures and support innovative policies. Finally we draw some conclusions for practical regional policy in a 'learning region'.

KEY WORDS $\star$ actor-centred institutionalism $\star$ network theory $\star$ regional governance

\section{Regional policy learning as a precondition of regional development}

It is generally conceded that regions have to be able to adjust their economic structures, their institutional frameworks and their policy programmes to changing conditions in order to improve their competitiveness in a globalized economy. For this reason what is usually designated as 'policy learning' (Bennett and Howlett, 1992) has become a decisive prerequisite of successful economic development. Regions have to develop capabilities systematically to adjust to changing circumstances without too much delay and without being forced by external pressure (Nonaka and Reinmöller, 1998). These assumptions are supported by theories on regional development prevailing in current discussions. They suggest that autonomous policy making in a region is important

for regional competitiveness and development because autonomous regions are more flexible in adapting to changing conditions and are more able to learn (Storper, 1997; Van den Berg et al., 1997). Adjustments of structures must be achieved by the region and cannot be decreed or determined by external authorities. As a rule, processes of policy change give rise to mounting resistance among those interested in maintaining the status quo. This requires the modification of previously intended or necessary adjustments during the process of change, which again refers to collective learning and negotiating to compensate those who risk becoming losers.

Why do some regions evolve into successful 'learning regions' while others do not? What are the specific conditions of learning in regional policy? How should regional governance be designed in order to improve the capacities to learn? And how 
should a regional development strategy look in the face of demands for continuous innovation? It is the aim of this paper to put forward some possible answers to these questions. Although we limit the discussion to formulating hypotheses, with testing being postponed to later empirical studies, we draw on empirical evidence derived from several studies on German regional policy.

We start from the assumption that competitiveness of regions is determined by their ability to organize 'endogenous learning processes' and to create the favourable resonance structures for policy learning. 'What is decisive is learning and innovation in a way that is specific for a region and which leads to the improvement of the particular regional comparative advantages, that distant rivals cannot match' (Porter, 1998: 78). Regarding strategies of regional policy, we acknowledge that regional development consists of interrelated processes leading to a kind of 'systemic' development. The challenge regions have to deal with is that successful changes and innovations mainly result from a simultaneous modification of different elements of structures and patterns of action. This is even more true since the continuation of historical development trends can no longer be regarded as an adequate regional strategy in the face of imminent challenges. Rather, path-dependent processes have to be changed by far-reaching interventions into those elements of the regional context that support an ongoing development.

We further assume that regional policy learning is a special case of policy learning: it is a process of collective learning geared to a strategy of regional development with those actors participating who contribute to regional development. We therefore suggest that the specific attributes of regional policy learning are as follows:

- the territory is the field of reference, not single projects;

- learning is a process of collective action, that is it concerns cognitive patterns as well as structures of interests;

- changes in patterns of participants' action and interaction are a decisive precondition for effectively governing regional development.

In the following we define 'regions' as areas of action above the local authorities and below state level which generally are either only weakly institutionalized or not organized at all. 'Regional development' refers to economic restructuring and improving the productivity of regional resources. 'Learning' is considered 'successful' if the dominant actors have adjusted their potentials to changed conditions and are better positioned to cope with them. Regaining 'competitiveness' would be a major result. However, learning is a process. Hence, not all the regional actors will have to change at the same time, with some taking the lead and others following later on.

\section{Lessons to be drawn from theories of regional development}

Different theories of regional development have contributed to the issue of regional learning and regional innovation. The most important ones are the theory of regional milieux, evolution theory and network theory. 1 The latter includes recent strands of discussion on 'learning regions' (Morgan, 1997), 'regional innovation systems' (Cooke, 1998) and 'regional governance' (Rhodes, 1996) respectively (Blotevogel, 1999; Fürst, 2001). ${ }^{2}$ When scrutinizing the different theoretical approaches we are interested in how they deal with learning, with collective action and with the conditions favouring learning.

Proponents of milieu theory emphasize the relevance of social, cultural and political conditions as prerequisites of successfully adjusting regional structures and policies (Camagni, 1995; Maillat, 1998). ${ }^{3}$ Dominant traits are cultural characteristics stimulating solidarity, cooperation, social relationships and dense patterns of communication; but the availability and the effective use of knowledge are deemed important, too. Recently the term 'social capital' has been applied to summarize these factors (Putnam, 1993; 2000; for a critical review see Harriss and de Renzio, 1997). From these considerations further preconditions for regional learning can be derived. Apparently, social relationships and structures of communications must be supported, inter alia, by a plurality of actors and shared traditions. In addition, the theory of regional milieux raises awareness of resources and institutional conditions of innovations, such as training facilities, research institutions, and systems of knowledge as well as institutionalized procedures 
and rules of policy making. The milieu theory is based on a structuralist approach focusing on 'territorial production systems'. It explains innovation and learning mainly with reference to characteristics of the 'systemic' conditions. Processes and interactions in which innovations are generated and implemented are taken less into consideration.

This is the point where network theory comes in. ${ }^{4}$ Networks are weakly institutionalized patterns of cooperation, thus creating an adequate framework for innovative interactions. The approach is based on an action theory which explains outcomes of processes on the basis of the utilitarian orientation of actors. Participants in a network are motivated to learn by the promise of new opportunities, they achieve better access to new information and profit from reduced transaction costs when collectively seeking new solutions to collective problems (Scheff, 1999). Whether and to what degree networks can promote policy learning in regions depends on the structures of networks, the patterns of interaction and the (structurally induced) abilities of members of a network to manage conflicts. However, networks are no panacea for learning. They may enable learning through the density and stability of communications in networks, but there is also the risk that they may simply support the conservative behaviour of actors bound to traditions and routines (Grabher, 1993; Rösch, 2000).

Advocates of network theories follow a problem or issue-oriented approach. In this view space and territory are of minor importance. A region fulfils at best $-\mathrm{a}$ 'facilitating function', and is of limited relevance for explaining capabilities to learn.

Therefore, proponents of the theory of 'learning regions' claim to go beyond this approach and try to integrate ideas of the milieu approach. They point out that the ability of a region to learn and innovate depends much on the regional context: on patterns of interaction, on social and cultural values and ideas, on organizations designed to support the generation of knowledge and innovation, on the institutional setting and, in particular, on the way new knowledge is used. According to this theory, learning consists of the combination of existing and new knowledge in order to find new ways to solve problems (Lawson and Lorenz, 1999). In that sense learning could mean different things: adopting solutions which were already successfully applied in other regions (lesson draming: Rose, 1991; or policy transfer, Dolwitz and Marsh, 1996), or adjusting imported solutions to the specific problems of a region. Or it can lead to the generation of entirely new solutions. Under what conditions and in which way these different varieties of regional learning become effective, is still an open question.

Proponents of the theory merely agree that three factors may explain different ways of learning: the development path in the past, the accessibility of 'tacit knowledge' and the transaction costs of change (see Lawson and Lorenz, 1999).

But can processes of learning be effectively controlled and shaped by regional actors in order to achieve specific goals? Here, scholars following the evolution theory are more sceptical. They emphasize the difference between adaptation and adaptability. Adaptation can contribute to a specified goal but it can also preserve existing structures. In contrast, adaptability aims at the region's ability permanently to adjust to new conditions. Evolution theory conceptualizes learning on the basis of trial and error, with collective learning systems not necessarily being organized processes (learning from policy results). However, they draw on sufficient redundancy and 'boundary spanning units' linking different subsystems of the regional structures. These factors should allow exploitation of the range of information and options for problem solving (Grabher, 1994; Grabher and Stark, 1997).

All these theories provide valuable suggestions and hypotheses as to preconditions of bringing about effective learning. They draw attention to favourable cognitive and socio-cultural backgrounds (theory of regional milieux), to processes of communication and interaction (network theory), to resources and institutional settings adequate for managing know-how ('learning region') and to redundant options for policy making (evolution theory). However, in all theories learning is treated as a result of collective action without explaining why and how these processes evolve. The following analysis departs from this state of discussion. We are interested in finding out which structures and processes of regional governance may make a difference between learning regions and regions not able to innovate. We assume that the organization of regional governance is the decisive variable to explain the learning capacity of a region.

For this reason the recent discussion on 'regional 
governance' is of considerable relevance to our analysis (Le Galès, 1990; 1997; Rhodes, 1996). Nevertheless regional learning is still a peripheral subject in the discussion on 'governance'. The problem of learning and innovation is on the research agenda, but available analyses have so far not contributed very much to advancing our knowledge. Obviously regional governance has to link institutionalized structures of governance with the more informal patterns of policy making. Also, we have reason to believe that regional networking is a crucial element in the management of this linkage. Apparently, the density of interactions and communication in networks can stimulate learning, but we do not know under what conditions this is really the case. Which specific patterns of 'regional governance' enable learning and innovation, and which patterns give rise to conservative policies - is the subject we deal with in the following sections.

\section{Policy learning in regional networks}

As mentioned above, a learning region can be defined as a region which actively responds to new circumstances and adjusts its programmes, institutions and the allocation of 'collective goods' in order to improve the productivity of resources. Such a region should - in the terms of Argyris and Schon (1978) - be able to achieve 'double loop' learning and preferably 'deutero' learning. At least it should change the internal preconditions of regional policy making (double loop learning), if it is not successful in turning regional structures into a continuously adjusting and innovating system (deutero learning). In any case it should go beyond a mere change in the application of existing policy instruments and should affect both the basic goals of regional policy and the set of actors involved in regional policy (social learning, Hall, 1993).

Supported by the theories discussed above we assume that networks provide for such a quality of learning. However, networks are not 'learning systems' per se. Compared to formal organizations they have the advantage of including loosely coupled patterns of communication and negotiation. Policy making in such a setting is normally more open to external stimuli and more responsive to changing circumstances as they comprise more 'boundary spanning units'. But the internal mode of dealing with external impulses may be inadequate:

- Networks may constitute cartels of actors interested in preserving the status quo. In this case, they tend to react to impulses for change with adjustments minimizing cost and conflicts (for instance by ignoring the real demand for change; by symbolic instead of effective adaptation, by deferring necessary changes in time-consuming consultation and by shifting the problem to committees).

- Networks may come under stress and produce overreactions. Struck by confusion, they may implement reforms which are not well designed, or react in panic with immediate transformation of routines and structures. Such developments can generate enormous transaction costs which ultimately may obstruct further changes.

- Networks may break up, if it is not possible to unite 'modernizers' with 'traditionalists', if these actors do not cooperate in policy making.

Therefore, even if networks constitute favourable conditions for regional policy learning, they may also impede learning. In order to assess the conditions under which networks promote a more innovative or a more conservative policy, we combine the concept of policy learning with the analytical model of collective action inherent in the approach of an actor-centred institutionalism (Mayntz and Scharpf, 1995; Scharpf, 1997). According to this approach, we regard regional learning as a process which requires that both actors and the collectives of actors learn (Wiesenthal, 1995: 139). This multilevel perspective distinguishes our theory from the theories mentioned above, in particular from the system-theoretical approach predominating in the discussion on learning regions. In addition, by following this approach, we include the political aspect of policy learning. Learning must therefore be combined with a process of collective (or political) action that reallocates resources or changes institutional structures. Beyond the generation and the processing of information (the cognitive dimension), the quality of learning hinges on the management of conflicts and cooperation (the political dimension). 5 Thus the capacity of a region to learn can be defined by its ability to generate and diffuse new information as well as to solve conflicts resulting from policy 
changes. Processes of collective action are influenced by the institutional framework (which can be modified) as well as by external constraints. But in addition, the number and type of actors, action orientations of actors, patterns of interaction and the situation actors are in constitute relevant factors influencing policy making.

Therefore, leaving aside the institutional setting of regional governance and the external constraints in a first step of our analysis, we assume that successful regional learning and effective adaptation depend on at least four characteristics of regional networks: the structure of the network; actors' action orientations; the autonomy of actors; and the dynamics of networks.

\section{Network structures}

With respect to the management of information, the capacity of a region to learn is dependent on structures of networks. Cognitive innovation is increasing, the greater the variety of competent actors, the more these actors can participate with equal rights and the more intensive their relationships to the outside world. Heterogeneity of participants as such increases the amount of different knowledge and orientations of actors. It implies a plurality of belief systems and cognitive frames which allow networks to cope with complex and ambiguous information (Wiesenthal, 1995: 151). Equality of actors in a polyarchic structure promotes the horizontal flow of information into all parts of a network. External relations generate additional information not available in a region. However, these structural features of a network may be unfavourable regarding the management of conflicts in the process of learning. Heterogeneity of actors implies, as a rule, a plurality of interests to be dealt with. In polyarchic structures, many actors have to negotiate on conflicts. Negotiations often end in compromises which - because of the veto power of those interested in preserving the status quo - conserve existing structures. Innovative solutions of conflicts require a hierarchic structure in which powerful promoters of changes determine policies. Intensive external relations often raise the level of conflicts because actors are inclined to distrust new information from outside, in particular if it produces 'cognitive dissonance'. Proposals for changes which are not elaborated inside the region can easily be rejected for not fitting in the particular circumstances. Moreover, the costs of innovation are overestimated if innovations are induced externally. Obviously, when searching for optimal structures of networks for learning we end up in a dilemma.

Successful regions can evade this dilemma in the following ways:

- If structures differentiate between core groups and peripheral groups, the region can profit from heterogeneous sources of information and at the same time manage conflicts in a more homogenous core group.

- This differentiation allows for a reinforcing combination of polyarchy and hierarchy. Multiple actors (polyarchy) negotiate in the 'shadow of hierarchy'. The core group can intervene and decide conflicts (shadom of hierarchy) if negotiations fail to produce effective solutions.

- Successfully learning regions are able to incorporate actors with intensive external relations into core networks in order to transform external challenges into internal processes of innovation.

These differentiated structures of networks cannot be expected to emerge automatically in the evolution of regions. Rather, whether they exist or not depends on the network management (Gage and Mandell, 1990) of promoters. Managers of networks often come from 'intermediary' institutions like chambers of industry and commerce or universities. In Germany, the intermediary position of regional administrations such as the regional districts (Regierungspräsidien/Bezirksregierungen) or the county governments enables the leaders of these administrations to achieve the positions of powerful and competent network managers. In addition, the specific political culture of a region is an important factor in stabilizing differentiated networks. This is particularly the case since the political culture will influence the orientations of actors.

\section{Actors' orientations}

By 'actors' orientations' we describe actors' general attitudes concerning their strategic behaviour and 
their relations to others (Scharpf, 1997: 60). Actors may be 'system-oriented' or 'selfish-oriented', 'competitive' or 'cooperative', risk-friendly or riskaverse. Learning in an organization or a network requires that actors be able and willing to learn as individuals and that they join in mutual learning. If we take cognitive capacities of individuals as given, then actors' learning depends on their action orientations.

It is often assumed that the competition of actors will induce them to look for innovative strategies. Competitive orientations stimulate an individual to search for information because information is a decisive resource in economic processes as well as in political power games. However, competitive orientations could be detrimental to collective learning since competitive actors tend to exclude others from the use of information. Apart from igniting conflicts, this strategic behaviour may thus prevent collective learning in a region. Rather, taking into account the political dimension of regional learning, one would expect better results if actors were to cooperate. Hence a mixture of competitive and cooperative action orientations seems to be required.

In addition, collective learning is facilitated if actors can rely on solidarity with other actors and can trust in their cooperation. Interpersonal relations based on social capital are less jeopardized by competitive behaviour; rather competition combined with cooperation may stimulate productive conflicts. Such relations enhance actors' consciousness for collective concerns, discourage selfish behaviour of individual actors and motivate actors to regard regional development goals as congruent with their own interest. Therefore, social capital seems to be essential for regional learning (Blotevogel, 1999: 57). It reduces the costs of transactions and contributes to stable communicative and cooperative relations. Social capital could enable collective learning within a competitive environment.

In order to create such action orientations in regional networks, several supporting conditions seem to be helpful, if not obligatory. One is the political culture of a region. However, there is more to it than just a political culture encouraging cooperation and valuing the striving for collective goods in the region. We assume that the combination of competitive and cooperative actors is more likely in a 'pluralist' regional culture than in regions with stronger social norms pressing for conformity. This is the reason why trans-border regions are often more innovative than oldestablished regions with strong traditions. Pluralist cultures produce more diverse cognitive and normative action orientations, but they also force actors to work more intensively for the integration of a region.

To a certain degree, promoters of the regional interest can influence action orientations if they are acknowledged as legitimate representatives. Also promising is the inclusion of actors with different orientations in regional networks. Thus, competitive orientations may be stimulated more by actors coming from private firms, whereas actors from regional public institutions and associations may reinforce cooperative orientations. Actors from the public sector may be more risk-averse than private actors due to their commitments to institutions and political parties. However, representatives coming from regional industry and commerce may confront public officials with new ideas and even take on the role of mediators in regional politics. Therefore, regional cooperation should be rendered attractive to private entrepreneurs. German experience shows that entrepreneurs and even their associations feel less bound to the region than to supra-regional networks of actors, and regard 'regional conferencing' as time consuming. They do not recognize a common added value which would make regional cooperation worthwhile to them.

\section{Autonomy of actors}

It can be assumed that creative learning (trial-anderror-learning with uncertain results) will be most effectively undertaken by actors enjoying considerable autonomy. But actors who become autonomous by reducing linkages with others may be excluded from external impulses for innovation and may be reluctant to cooperate and to share their experience with other actors. Therefore, to judge the consequence of actors' autonomy for regional learning we should distinguish between internal and external autonomy. Internal autonomy is related to an actor's position inside the regional networks and refers to the actor's capacity to initiate 
and find acceptance within a network. External autonomy refers to independence from actors and structures outside the region and is determined by the competencies and resources of organizations influencing the region's development and by the way a region is embedded into multilevel structures of government.

Learning within regional networks is stimulated by information exchange and communication.

Hence, innovations may be encouraged by communicative structures that allow for joint policies. While limited autonomy of actors may reduce conflicts in the learning process, there is no doubt that it diminishes the probability of individual actors providing innovative impulses. Dependent actors often follow cognitive routines and strongly take vested interests into account. Tendencies to privileging the status quo are further intensified if 'group think' effects take place (Janis, 1972). Moreover, the more the actors depend on each other, the more they can exploit veto powers. Therefore it could be argued that the lower the internal autonomy and the stronger the interdependencies of actors in regional networks, the more likely it is that regional policy changes will be reduced to incremental adjustments. Comparable findings can be found in empirical studies on 'interlocking politics'. They may contradict observations in organization sociology where strong ties are regarded as more likely to break the path for changes while weak ties are associated with incremental changes. Whether the one or the other is the case depends on whether the actors are willing to move in the same direction or have conflicting ideas as to where the change should lead to. In regional development it seems more realistic to assume that the actors hold differing perceptions regarding changes. Weak interdependencies allow actors to voluntarily join allies for innovation while leaving out those not (or at least less than others) willing to change. Weak ties allow for the exit-option, thus reducing the need to compromise on the smallest common denominator.

Regarding external relations, we expect actors to be most innovative if influenced by developments from outside the region. In this case, impulses to adapt are strongly felt and induce regional actors to learn. Autonomous regions with sufficient power to ward off external institutions can afford not to learn. However, if individual actors are externally dependent their freedom to cooperate in regional policy processes is strongly constrained.

From this it follows that loosely coupled networks provide the best preconditions for regional learning. ${ }^{6}$ Yet it is not networks as such which are important but rather their ability to promote the development of small network cores in which innovative impulses can emerge and from which they subsequently spread to other members of the regional network. External relations must be loosely coupled, too, in order to make innovative regions take advantage of outside knowledge. Those external relations, however, can become an impediment to innovation if they make the region resource dependent and hence vulnerable.

\section{The dynamics of networks}

Networks have to deal with situations that may induce policy learning but can also imply uncontrollable turbulence. Whether a given situation elicits collective action depends on how actors perceive and define the challenges for acting. It is not the 'objective' situation that is relevant but the perception and definition of a situation concerning the demand for change, the controllability of developments and the realistic potential for change (perceived solutions).

Therefore, the existing knowledge is decisive and whether situations lead to regional learning depends largely on actors' openness to new knowledge, for new ideas and cognitive impulses. If discussions on changes are suppressed in a network and if new policies are not allowed to get onto the agenda, then challenging situations cannot induce learning. The readiness to accept new ideas largely depends on the stability of existing dominant coalitions of actors and their perception of the situation as well as of suitable solutions.

Nevertheless, regions can be pressed to learn by crisis situations. We often observe that high pressure problems break up existing coalitions. The decline of industries, for example, regularly destroys traditional patterns of perception and delegitimizes the power of those linked to old industries while new actors gain political support. But it depends on whether the actors perceive that the outcome of solutions which they are willing to address can be 


\begin{tabular}{|c|c|c|c|}
\hline \multirow{3}{*}{\multicolumn{2}{|c|}{ Attributes of regional networks }} & \multicolumn{2}{|c|}{ Conditions concerning the } \\
\hline & & cognitive dimension & political dimension \\
\hline & & \multicolumn{2}{|c|}{ of policy learning } \\
\hline \multirow{3}{*}{$\begin{array}{l}\text { structure of } \\
\text { networks }\end{array}$} & homogeneity & low & high \\
\hline & power structure & polyarchy & hierarchy \\
\hline & $\begin{array}{l}\text { external } \\
\text { relations }\end{array}$ & open: intensive external contacts & closed: limited external contact \\
\hline \multirow{2}{*}{$\begin{array}{l}\text { actors' } \\
\text { orientation }\end{array}$} & $\begin{array}{l}\text { strategic } \\
\text { behaviour }\end{array}$ & competitive & cooperative \\
\hline & $\begin{array}{l}\text { interpersonal } \\
\text { relations }\end{array}$ & \multicolumn{2}{|c|}{ trust (social capital) } \\
\hline \multirow{2}{*}{$\begin{array}{l}\text { autonomy of } \\
\text { actors }\end{array}$} & internal & high & low \\
\hline & external & low & high \\
\hline $\begin{array}{l}\text { dynamics of } \\
\text { networks }\end{array}$ & $\begin{array}{l}\text { stability of } \\
\text { coalitions }\end{array}$ & low & high \\
\hline
\end{tabular}

Figure 1 Conditions for successful regional policy learning in networks

controlled. There is also the possibility that a crisis leads to conservative reactions. That may be the case if a crisis situation becomes too severe and blocks collective learning because the actors are unable to reach a consensus on what to learn and how to cope with the insecurity of the developments. Hence, even though traditional paradigms of how to manage situations and conflicts may no longer be valid, actors choose a conservative strategy rather than an innovative one since the status quo can be agreed upon while the innovative strategy cannot. Again, weaker actor ties could be more inducive to changes since they would allow those willing to risk change to do so.

\section{Summing up the argument}

To sum up, our theoretical reasoning is based on three main strands of argument. First, we use the concept of actor-centred institutionalism which links individual decision making to the institutional framework in which it takes place and includes collective as well as individual actors. Second, we assume that innovative regions must resolve both types of problems: a cognitive task to identify the need for action and the (technical) way in which issues should be resolved, as well as a political task to reconcile winners and losers of change in a joint strategy. Third, we use network theory to analyse patterns of regional structures that work as facilitating intermediaries both between the political and cognitive task and between the individual and collective actors. We thus follow the line of reasoning developed in the discussion on 'policy learning in policy networks' (p. 23). According to that, networks allow a region to improve its ability for changing policies and to renovate the structural context for regional policy making.

In a nutshell, our analytical basis can be summarized as shown in Figure 1.

If our hypotheses are correct, regional learning networks have to comply with different - to a certain degree contradictory - criteria regarding the cognitive and political dimensions of policy learning. On the one hand the management of information (detection of demand for change, mobilization of new or tacit knowledge, finding new solutions) requires pluralistic, polyarchic and open networks including competitive and internally autonomous actors in flexible but intensive patterns 
of communication. On the other hand, the effective solution of conflicts is more likely in homogeneous, hierarchical and closed networks with cooperative, interdependent actors forming stable coalitions of change-promoters.

Therefore, to rely entirely on networks is insufficient. The contradictory criteria can only be met in more complex structures or more complex modes of regional governance, that is by an adequate mix of networks and institutions.

Moreover, it is obvious that an intelligent management of networks in regional policy is essential to avoid both unmanageable turbulence and merely minor reactive adjustments. This raises two questions. How can the different demands be met in creating regional governance? How can regional policy, which is designed to promote development by creating a learning region, influence the structures and dynamics of networks?; that is, how can a strategy of network management be integrated into regional development policy?

\section{Learning networks in regional governance}

With the term 'governance' we describe networkbased modes of collective action including organized regional actors or institutions (Pierre, 2000). When introducing the concept of regional governance, not only the notion of 'region' becomes questionable but also the assumption that regional policy learning is mainly determined through networks and less though institutions.

Indeed, many recent studies show that only certain regions constitute an integrated unit of action (Hellmer et al., 1999). As a rule, most policies in regions refer to projects. Actors design their strategies for development on the basis of a costbenefit calculation of specific projects. They cooperate in networks if they recognize joint issues or mutual resource dependency. Thus, for policy learning within networks the concept of the region is of only secondary importance. However, participants of issue-networks will take into consideration the territorial context since it is related to interdependencies of actors providing the basic motive for cooperation. This holds true not only for representatives of regional institutions but also for private firms, as the 'new economic geography' has shown (Krugman, 1998). In addition to the positive external effects of urban and locational economies, the region's social capital has become a crucial advantage for private firms. Therefore, even if we agree that regional policies and regional networks mostly refer to projects, the regional space is the essential structuring framework for networks of regional policy and for regional governance. However, the territorial boundaries of administrative or political units do not matter, rather the 'region' is defined by the scope of function-specific interdependencies and interactions. 'Unlike the spaces covered by territorial authorities and local administrative districts, this space is constituted through various forms of cooperation between actors and organizations that pool their actions and resources in order to promote and shape regional development on a joint basis' (Benz et al., 2000: 14).

But focusing on networks is questioned in the literature given the predominance of institutions in policy making - at least in countries like Germany (see Hellmer et al., 1999). We do not agree with this opinion. As recent studies have shown (Ansell, 2000; Benz et al., 2000, Le Galès and Lequesne, 1997), in most modern states regions are levels of policy making with only weakly institutionalized structures. The principal political decisions are made at the central (federal and Länder) or the local level. However, due to changes in the state and economy, ${ }^{7}$ the region has attracted increasing attention, not least influenced by EU structural policy. It is true that regions are less institutionalized than other political units. But it is exactly this 'deficiency' that makes them attractive for actors interested in flexible cooperation in networks crossing the boundaries between the public and the private sector.

Against the emphasis on networks as part of regional governance, it is often argued that policy making in networks is highly dependent on the given situation, and that networks cannot implement rules for guiding actions. They are said to be dependent on persons and the composition of groups of participants. However, this argument is only partially convincing. On the one hand, persons do matter even in institutions. But the effectiveness of institutionalized rules declines while deregulation increases and public-private cooperation gains growing importance in public policy. On the other 
hand, networks generate rule systems of their own because their weak formalization is compensated for by participants' accepted roles, social norms and self-discipline. The advantage of networks rests less on their freedom from institutional constraints than on the fact that they are open to new actors and issues, less bound to decisions made in the past and hence more likely to give impulses for innovation by constituting intermediary structures and facilitating inter-actor negotiations (Mayntz, 1992).

However, since networks can fulfil only intermediary functions in the institutional setting, they cannot replace legitimizing political institutions (Benz, 1996). Therefore, policies prepared in networks have to be accepted and implemented in formal institutions. From this it follows that the existing structures of institutions will influence the processes within the networks and shed 'their shadow' on the actors' behaviour as well as on the networks' potential outcome. This is the general fate of any intermediary structure. In addition, actors participating in networks are not only committed to institutions (external to the networks), but gain legitimization, competencies and resources from their institutional background.

The strong context-dependency of network-base governance patterns makes for differences in regional governance and may contribute to differences in the regional potential to innovate. To some extent, the institutional background makes networks vulnerable to external influences and may reinforce internal deficiencies of cooperation. Even behaviour learned in institutions could impair networks. Actors adhering to bureaucratic routines can obstruct innovation processes in networks. Or, actors not accustomed to formal proceedings or to cooperation with others may cause blocking effects.

Therefore, the structure of the institutional setting is a decisive element in shaping governance of learning regions. By 'institutional setting' we mean rules and organizational structures that interfere and frame the network cooperation. The institutional setting defines resource-dependencies and structures of control, stabilizes expectations and links the network to those administrative units that finally have to implement the network results. The importance of the institutional setting does not contradict the fact that policy learning mainly depends on interactions in networks.

From this it follows that policy learning in regions requires a type of regional governance where the institutional setting could create an appropriate network structure. Although networks must work relatively autonomously from institutions, they have to be embedded in an adequate manner in institutions. Supportive institutions would provide capacities for solving conflicts and for producing legitimate decisions, without suppressing the emergence of loosely coupled networks.

Hence we might come to the conclusion that institutions are important in order to reconcile the contradictory demands a learning region imposes on the relevant actors which cannot be met by networks themselves. If regional learning is to be 'troublefree', networks and the institutional setting should be consistent in such a way that there exists some kind of division of functions: the former would serve the cognitive tasks of policy learning, while the political functions (that is, the management of conflicts) would have to be taken on by institutions. However, such a 'division of functions' between networks and the institutional setting is only a theoretical one because such arrangements would make regional governance vulnerable to disintegrative processes. The innovative power of networks characterized by heterogeneity, polyarchic structures, intensive external relations, competitive and internally autonomous actors as well as by dynamic coalitions could be stifled in an institutional setting which fosters integration, compromises, cooperation, control and stability. However, an institutional environment inducing a highly competitive climate, stronger tendencies towards distrust and a weak sense of regional solidarity may strain network cohesiveness and thus reduce its potential to elicit synergetic effects.

Therefore, learning regions apparently need a type of regional governance in which both networks and institutions are optimized with regard to both the cognitive and the political aspects of policy learning. Network structures, according to our reasoning, would require

- the differentiation between core networks and peripheral networks, with the latter being more heterogeneous, polyarchic and open to external contacts, and the core networks consisting of homogenous actors with strong internal ties and power to control the dynamics of policy learning; 
- a plurality of overlapping networks focusing on specific functions in regional policy and competing for resources in the region;

- the existence of network managers with the power to mobilize participants in networks and to maintain a balance between the stability and dynamics of network structures.

'Optimization' will, however, be mainly the task of the network structures since the institutional setting is hardly flexible enough to do the job. It is then a question of whether the 'optimal arrangements' emerge automatically or whether they must be organized. At least there are supportive framework conditions defined by an adequate institutional setting. Optimization processes may then be expected to emerge in those institutional settings that include the following elements:

1. A regional council comprising representatives from all relevant social groups and local governments. This council should be responsible for final decisions on fundamental issues (such as development goals, planning schemes or the allocation of resources). German experiences with regional planning organizations reveal that such councils are able to provide a basis for the creation of polyarchic regional networks because they introduce a multitude of more or less competing actors from different sectors into a joint regional policy process. At the same time, they are acknowledged as legitimate institutions for solving conflicts (Benz et al., 2000: 51-78 ; Knieling et al., 2001).

2. Boundary-spanning institutions, that is institutions incorporating different functions (like the German Regierungspräsidien/Bezirksregierungen) or cutting across the public-private divide (like the Chambers of Industry and Commerce or NGOs). Supported by effective networks, leaders of these institutions are able to mediate conflicts between different interests. Not only their neutrality but also their legitimacy predispose them to play the role of mediators and managers of networks.

3. An independent agency endowed with the power to initiate policies (preparation of 'Regional

Development Concepts'), to manage the implementation of projects and to evaluate the outcome of regional policies. Such an agency could initiate innovations with its leaders adopting the role of promoters for change in policy networks. Due to their independence from established politics and their professional competence they are able to act as regional 'playmakers' (Benz et al., 2000: 135). 4. And, finally, a central government which abstains from strict control and instead sets an institutional framemork and standards for interregional competition. Regarding the embeddedness of a region in multilevel governance, policy learning in regions needs a governmental framework which would give incentives for regional innovations but also provide the conditions for fair competition (by defining rules and securing equal start-up conditions).

The above deduced conclusions are in accordance with empirical research on German regions (Benz et al., 2000; Knieling et al., 2001). But comparative studies of regional policies and regional networks in different institutional structures must show whether the assumptions supporting our reasoning are valid in other institutional settings.

Whatever the results of further research, there is a broad consensus in the literature that regional learning is a decisive precondition for regional development. Therefore, any strategy of regional development must aim at improving the learning capacities of the region. But how can the concept of a learning region be integrated into a strategy of regional development?

\section{Policy learning and network management as a strategy of regional development?}

Discussing strategies for the 'learning region' entails addressing the problem of whether regions are capable of adopting practicable tools to create the necessary conditions for policy learning or whether the capacity to learn is entirely dependent on the existing structural conditions of a region. Should the latter be the case, this would add to explanations of why some regions are better able than others to adapt to changing framework conditions and hence to learn.

We are more optimistic and favour the first alternative. We believe we have reasons for this, since case-studies on regional policy making in Germany provide supportive evidence. In particular the experience of changing regional institutions and networks in North Rhine-Westphalia reveals that it is possible to shape regional networks according to 
the findings derived from our theoretical considerations (Zarth, 1997).

We therefore venture recommendations for a 'proactive' strategy of regional learning. From our reasoning we arrive at the following suggestions:

1. Since the structure of regional networks is influenced by the institutional setting, a longer term strategy should make the design of regional institutions an element of regional development policy. This does not require an overall reform of institutions, but regional policy should continuously evaluate the existing institutions with a view to reducing the transaction costs for institutional change.

2. Whether that is a task entirely to be left to the region is open to debate. A look at the German reality would suggest that it should be done as a joint task of regional and state actors, since some of the elements constituting the institutional setting are controlled by the state. A good example of such joint management could be the recent organizational change in the Hannover Region where the county, the local communities and the regional planning association have fused into one organization ('Region Hannover').

3. Regional policy as performed by the region should be regarded as a governance concept which takes into consideration the specific cultural traits of an individual region. It is about stimulating endogenous potentials via a systematic management of cooperation related to projects of regional development. A project-oriented network management should - on the one hand - encourage competition on an interregional scale. On the other hand, a regional management focused on projects is more promising as a means of supporting cooperative behaviour within the region. The latter is important for accumulating positive experience in cooperation, while networks could help to generate a cooperative culture and the social capital required for a learning region. This could be expected even though the more homogeneous, hierarchical and closed policy networks related to projects exist only for a limited time span.

4. But in order to prevent networks from becoming cartels for preserving existing structures, internal competition for ideas and innovation should be stimulated. It is in this way that conservative coalitions can be broken up and incentives for forming new networks dealing with new projects provided. How effectively this could be done is difficult to say. Competition could be organized by public discourses on best practices, or the state government could be supportive by distributing fiscal incentives on a bidding base (as is currently the case in Great Britain).

5. Finally, boundaries of regions should be taken as a strategic variable of regional policy. This is no plea for territorial reform. Rather, we think of shaping functional interdependencies and of regional networks. Learning regions should be able both to control their internal development and to adjust to external pressure. In order to enhance the region's ability to control its development, it seems imperative for the region to be able to integrate external actors into regional networks or to extend its boundary-spanning networks among regions or between regions and higher levels of government.

These recommendations are based on the implicit assumption that policy learning is a two-level process depending on the behaviour of individuals and of collective actions. We expect that in a learning region both levels will interact to produce self-enforcing development. But what is the decisive point of departure? At the collective level, it appears that innovation must be initiated by external shocks or the intervention of a central institution. Yet, as we have tried to make clear, the outcome of such forced learning is uncertain. What seems to be more promising is learning that is initiated by individual actors. In this case, however, the transformation of regional structures into a learning region depends on the initiative of some creative, risk-taking and powerful actors. They could harness a supportive environment if there is a generally accepted need for change. Hence, learning regions must organize the supportive framework conditions for becoming innovative. But the necessary condition is that the region's traditional perception of its development paths and perspectives should have been questioned. This 'unfreezing' of traditional attitudes and modes of action will hardly be achieved by autonomous acts of the region. Rather, they will usually be induced externally, either by external impacts or by general 'paradigm changes' within a national setting.

Therefore, learning regions are not isolated regional systems that entirely rely on themselves, but are rather embedded in a supportive 
environment. To a certain degree they are even dependent on the Zeitgeist of the society to which they belong.

\section{Notes}

1 French 'regulation theory' (e.g. Jessop, 1995) which plays a certain role in approaches to regional development does not contribute very much to answering our research question. On the one hand, it focuses on macro-economic and macro-social structures and processes, and on the other hand it describes causes of necessary learning without explaining how and under which conditions learning processes are effective. While the main concerns of this theory are harmonies and disharmonies among regimes of accumulation and governance regimes, and the solution of social conflicts emerging during the evolution of regimes, it does not include any substantial theoretical statements on regional learning and innovation.

2 Both innovation approaches come to identical results concerning the prerequisites of innovation. The concept of 'regional innovation systems' suggests an active integration of all organizations, institutions and actors relevant for innovation into a 'system'. Actually, albeit not explicitly, the concept of 'learning regions' implies the same propositions.

3 'A territory's attraction is no longer a function of the locational factors it offers but of its production system's ability to create specific resources and to generate innovation processes' (Maillat, 1998: 9).

4 There is no single network theory. On the contrary, we find a variety of approaches with different heuristical foci. The definition of the concept of network depends on the research interest of the analyst. Tanja Börzel (1998: 255) recently distinguished two basic strands of network theory, one referring to intermediation of interests and policy making and the other referring to 'governance'. Moreover, network theory is often combined with elements stemming from other theories. For instance, the theory of regional milieux includes the concept of networks (Maillat, 1998), although it does not deal with the processes in networks.

5 In following this approach we deviate from 'constructivist' or 'interpretative' approaches of policy learning predominating in the literature of policy making and international politics. Here, learning is mainly conceptualized as change of ideas, paradigms or of cognitive frames (Braun and Busch, 1999; Goldstein and Keohane, 1993; Hall, 1993; Jachtenfuchs, 1996). What is underestimated in these studies is that in collectives, such processes lead to conflicts among actors affected by changes in different ways. Learning does not merely depend on cognitive dispositions of actors but also on rational interests and structures of power.

6 Networks are often defined as loosely coupled structures. However, we propose to distinguish networks by the degree of dependence among actors. Strong ties (strict coupling) exist in networks which connect actors by resource dependence; weak ties (loose coupling) are characterized by mutual influence through communication.

7 The most important changes are: the extension of action spaces beyond existing boundaries; the increase of interdependencies between policies and between the public and private sectors; the evolution of new forms of policy making by cooperation and negotiation; the simultaneous centralization and decentralization; and processes of deregulation.

\section{References}

Amin, A. (1999) 'An Institutional Perspective on Regional Economic Development', International Fournal of Urban and Regional Research 23: 365-78.

Ansell, C. (2000) 'The Networked Polity: Regional Development in Western Europe', Governance 13 (3): 303-33.

Argyris, C. and Schon, D. (1978) Organizational Learning. London: Addison-Wesley.

Bennett, C.J. and Howlett, M. (1992) 'The Lessons of Learning. Reconciling Theories of Policy Learning and Policy Change', Policy Science 25: 229-50.

Benz, A. (1996) 'Regionalpolitik zwischen Netzwerkbildung und Institutionalisierung - Zur Funktionalität paradoxer Strukturen', Staatswissenschaften und Staatspraxis 7 (1): 23-42.

Benz, A., Fürst, D., Kilper, H. and Rehfeld, D. (2000) Regionalisation. Theory, Practice and Prospects in Germany. Stockholm: Fritze.

Blotevogel, H.H. (1999) 'Zur Neubewertung der Region für die Regionalentwicklung', in ARL (ed.) Europäische Einflüsse auf die Raum- und Regionalentwicklung am Beispiel des Naturschutzes, der Agenda 2000 und des regionalen Milieus (Arbeitsmaterialien Nr. 257), pp. 44-60. Hannover: Akademie für Raumforschung und Landesplanung.

Börzel, T.A. (1998) 'Organizing Babylon - on the Different Conceptions of Policy Networks', Public Administration 76: 253-73.

Braun, D. and A. Busch (eds) (1999) Public Policy and Political Ideas. Cheltenham: Edward Elgar.

Camagni, R. (1995) 'The Concept of Innovative Milieu and its Relevance for Public Policies in European Lagging Regions', Papers in Regional Science 74: 317-40.

Cohen, M.D., March, J.G. and Olsen, J. (1972) 'A Garbage 
Can Model of Organizational Choice', Administrative Science Quarterly 17: 1-25.

Cooke, P. (1998) 'Introduction', in H-J. Braczyk, P. Cooke and M. Heidenreich (eds) Regional Innovation Systems, pp. 2-25. London: UCL Press.

Dolwitz, D. and Marsh, D. (1996) 'Who Learns What From Whom: a Review of the Policy Transfer Literature', Political Studies 44: 343-57.

Fromhold-Eisebith, M. (1995) 'Das "innovative Milieu" als Motor regionalwirtschaftlicher Entwicklung', Geographische Zeitschrift 83: 30-47.

Fürst, D. (1994) 'Regionalkonferenzen zwischen offenen Netzwerken und fester Institutionalisierung', Raumforschung und Raumordnung 52: 184-92.

Fürst, D. (2001) 'Die "learning region" - strategisches Konzept oder Artefakt?', in H-F. Eckey (ed.) Ordnungspolitik als konstruktive Antwort auf wirtschaftspolitische Herausforderungen, pp. 71-90. Stuttgart: Lucius \& Lucius.

Gage, R.W. and Mandell, M.P. (eds) (1990) Strategies for Managing Intergovernmental Policies and Networks. New York: Praeger.

Goldstein, J. and Keohane, R.O. (eds) (1993) Ideas and Foreign Policy. Beliefs, Institutions, and Political Change. Ithaca, NY and London: Cornell University Press.

Grabher, G. (1993) 'Wachstums-Koalitionen und Verhinderungs-Allianzen. Entwicklungsimpulse und -blockierungen durch regionale Netzwerke', Informationen zur Raumentwicklung 11: 749-58.

Grabher, G. (1994) Lob der Verschwendung: Redundanz in der Regionalentwicklung, Berlin: Ed. Sigma.

Grabher, G. and Stark, D. (1997) 'Organizing Diversity: Evolutionary Theory, Network Analysis and Postsocialism', Regional Studies 31: 533-44.

Hall, P.A. (1993) 'Policy Paradigms, Social Learning, and the State. The Case of Economic Policy-making in Britain', Comparative Politics 25 (3): 275-96.

Harriss, J. and de Renzio, P. (1997) “"Missing Link” or Analytically Missing? The Concept of Social Capital. An Introductory Bibliographic Essay', Journal of International Development 9: 919-37.

Hassink, R. (1997) 'Die Bedeutung der lernenden Region für die regionale Innovationsförderung', Geographische Zeitschrift 85: 159-73.

Hellmer, F., Friese, C., Kollros, H. and Krumbein, W. (1999) Mythos Netzmerke. Regionale Innovationsprozesse zwischen Kontiuität und Wandel. Berlin: Ed. Sigma.

Hudson, R. (1999) 'The Learning Economy, the Learning Firm and the Learning Region', European Urban and Regional Studies 6 (1): 59-72.

Jachtenfuchs, M. (1996) International Policy-making as a Learning Process. Aldershot: Avebury.

Janis, I.L. (1972) Victims of Groupthink. Boston, MA: Houghton Mifflin.
Jessop, B. (1995) 'The Regulation Approach, Governance and Post-Fordism: Alternative Perspectives on Economic and Political Change?', Economy and Society 24: 307-33.

Knieling, J., Fürst, D. and Danielzyk, R. (2001) 'Kooperative Handlungsformen in der Regionalplanung. Untersuchungen zur Praxis der Regionalplanung in Deutschland', Hannover (unpublished).

Krätke, S. (1996) 'Regulationstheoretische Perspektiven in der Wirtschaftsgeographie', Zeitschrift für Wirtschaftsgeographie 40: 6-19.

Krugman, P. (1998) 'What's New about the New Economic Geography?', Oxford Reviem of Economic Policy 14: 7-17.

Lawson, C. and Lorenz, E. (1999) 'Collective Learning, Tacit Knowledge and Regional Innovative Capacity', Regional Studies 33: 305-17.

Le Galès, P. (1990) 'Du gouvernement des villes à la gouvernance urbaine', Revue Française de Science Politique 45: 57-95.

Le Galès, P. (1997) 'Gouvernement and gouvernance de régions: faiblesses structurelles et nouvelles mobilisations', in P. Le Galès and C. Lequesne (eds) Les paradoxes des régions en Europe, pp. 237-63. Paris: La Découverte.

Le Galès, P. and Lequesne, C. (eds) (1997) Les paradoxes des régions en Europe. Paris: La Découverte.

Maillat, D. (1998) 'Innovative Milieux and New Generations of Regional Policies', Entrepreneurship and Regional Development 10: 1-16.

Mayntz, R. (1992) 'Modernisierung und die Logik von interorganisatorischen Netzwerken', Journal für Sozialforschung 32: 19-32.

Mayntz, R. and Scharpf, F.W. (1995) 'Der Ansatz des akteurzentrierten Insttitutionalismus', in R. Mayntz and F.W. Scharpf (eds) Gesellschaftliche Selbststeuerung und politische Steuerung, pp. 39-72. Frankfurt and New York: Campus.

Morgan, K. (1997) 'The Learning Region: Institutions, Innovation and Regional Renewal', Regional Studies 31: 491-503.

Nonaka, I. and Reinmöller, P. (1998) 'The Legacy of Learning. Toward Endogenous Knowledge Creation for Asian Economic Development', in WZB-Fahrbuch, pp. 401-33. Berlin: Ed. Sigma.

Pierre, J. (ed.) (2000) Debating Governance. Authority, Steering, and Democracy. Oxford: Oxford University Press.

Porter, M. (1998) 'Clusters and the New Economics of Competition', Harvard Business Reviem (Nov./Dec.): 77-90.

Putnam, R.D. (1993) Making Democracy Work. Civic Tradition in Modern Italy. Princeton, NJ: Princeton University Press. 
Putnam, R.D. (2000) Bowling Alone. The Collapse and Revival of American Community. New York: Simon \& Schuster.

Rhodes, R.A.W. (1996) 'The New Governance: Governing without Government', Political Studies 44: 652-67.

Rösch, A. (2000) 'Kreative Milieux als Faktoren der Regionalentwicklung', Raumforschung und Raumordnung 58: $161-72$.

Rose, R. (1991) 'What is Lesson Drawing', fournal of Public Policy 11: 3-30.

Saxenian, A.L. (1996) Regional Advantage. Culture and Competition in Silicon Valley and Route 128. Cambridge, MA: Harvard University Press.

Scharpf, F.W. (1997) Games Real Actors Play. Boulder, CO: Westview Press.

Scheff, J. (1999) Lernende Regionen. Regionale Netzmerke als Antwort auf globale Herausforderungen. Wien: Linde.

Storper, M. (1997) The Regional World. Territorial Development in a Global Economy. New York and London: Guilford Press.

Van den Berg, I., Braun, E. and van der Meer, J. (1997) 'The Organizing Capacity of Metropolitan Regions', Environment and Planning C: Government and Policy 15: 253-72.

Voelzkow, H. (1999) 'Die Governance regionaler Ökonomien im internationalen Vergleich: Deutschland und Italien', in G. Fuchs, G. Krauss and H-G. Wolff (eds) Die Bindungen der Globalisierung: Interorganisationsbeziehungen im regionalen und globalen Wirtschaftsraum, pp. 48-91. Marburg: Metropolis.

Wiesenthal, H. (1995) 'Konventionelles und unkonventionelles Organisationslernen: Literaturreport und Ergänzungsvorschlag', Zeitschrift für Soziologie 24 (2): 137-55.

Zarth, M. (1997) 'Was macht Regionalkonferenzen erfolgreich?', Informationen zur Raumentwicklung 3: 155-60.

\section{Correspondence to:}

Arthur Benz, FernUniversität Hagen, Institut für Politikwissenschaft, Feithstraße 140/ESG, D-58084 Hagen, Germany. [email: arthur.benz@fernuni-hagen.de]

Dietrich Fürst, Universität Hannover, Institut für Landesplanung u. Raumforschung, Herrenhäuser Straße 2, D-30419 Hannover, Germany.

[email: fuerst@laum.uni-hannover.de] 